\title{
Possibilities in Enhancing the Security for Women using IoT
}

\author{
S. Philomina, M. Jasmine, K. Subbulakshmi
}

\begin{abstract}
In modern-day world ladies are much less comfortable and feature many issues regarding their safety cause. They should undergo amongst various tough situations and should Prove themselves in all significant circumstances every moment. For their safety and protection reasons, therefore, the authorities have provided security through policies and regulations to society. Despite the reality that there are many present safety-related systems, the need for superior smart protection gadgets is accelerated. In order to conquer such problems, smart safety gadgets are used for females. This document defines roughly a safe and secure digital phone for women, consisting of a NodeMCU, WiFi,which acts as a Transceiver and an IOT Bell,which will be fixed to all houses,shops,police stations etc... A router is introduced at certain zone which gives a wide bandwith organize.
\end{abstract}

Keywords: Women Security, WiFi

\section{INTRODUCTION}

Crime is an activity or can also be an exclusion that is an offense and must be preserved by law. In addition, wrongdoing is a legitimate concept where lawful wrongdoing by an person or a collection, i.e. criminal proceedings, leads to a guilty result. According to Lord Atkins, "the criminal nature of the demonstration can not be determined by reference to any standard, but one: is the feline that is excluded from the outcome of the reform." In India, the Criminal Procedure Code (Cr. P.C.) classifies each of the wrongdoings into two groups: $\mathrm{I}\{\mathrm{Sec} .2(\mathrm{c})$ of the Cr. It's P.C. (ii) $\{\sec (1)$ Cr. P.C $\}$.To put it plainly, an offense or case is defined as one which the officer responsible for the police headquarters may investigate without a judge's request and without a warrant for the capture of an impact and is ordered in a comprehensive manner in accordance with the Indian Criminal Code (IPC) or the Special and Local Laws (SLL), while unrecognizable wrongdoing is defined as those which can not be examined by the Indian Criminal Code (IPC) or the Special and Local Laws (SLL) [2],[4],[6]. There are a number of wide-ranging provisions for wrongdoing under the IPC-Crime against bodies such as assassination, seizure and looting, Crime against property such as dacoity,

Revised Manuscript Received on August 22, 2019.

S.Philomina, Department of Electronics and Communication Engineering, Bharath Institute of Higher Education and Research, Chennai, Tamilnadu, India. E-Mail - philomina.nov83@gmail.com

M. Jasmine, Department of Electronics and Communication Engineering, Bharath Institute of Higher Education and Research, Chennai, Tamilnadu, India. E-Mail- rifriz@gmail.com

K. Subbulakshmi, Department of Electronics and Communication Engineering, Bharath Institute of Higher Education and Research, Chennai, Tamilnadu, India. E-Mail - p.sudha50@gmail.com

burglary, robbery and burglary, Crime against property open-ended petitions such as uproars and pyro-crime, Economic violations, Crime against ladies like assault, settlement passing, pitilessness and ambush, importation of young ladies from outside nation, Crime against kids like kid assault, hijack and kidnapping, selling and purchasing, child murder and feticide2.

The cutting edge time We're living in an unreliable condition especially for the ladies. They are currently feeling unsure about ventureing out of their homes on their own because of the increase in wrongdoing levels like ; assaults, eve prodding, attack, theft, seizing and so on. The metropolitan urban communities like; Delhi, Mumbai, Kolkata and so on and substantial urban communities like; Bhopal, Jabalpur, Bhilai, Kota, Ludhiana, Raipur and so on. With regards to wrongdoing rates, it has been broke down they are confined to the impact of populace. Equally close to the population, economic aspects can also have an effect on the increasing amount of criminal offences. Madhya Pradesh and Uttar Pradesh were also answered to have the highest incidence of assault, assault, snatching, and the capture of women and youth. Madhya Pradesh portrayed 4882 cases of assault from 38,947 cases reported in the region, according to the 2016 NCRB report. The countries stayed at 348.3 at a high error rate, much greater than the domestic standard of 234. The state has been raising the list of sexual crimes for the last ten years. The number of attacks and full sexual abuse cases decreased by 11 per cent and 15 per cent individually this year, compared with 2014. In those days, 5,076 assaults and 15,170 sexual occurrences were reported by the state[1],[3],[5].

\section{LITERATURE SURVEY}

[1] In an article,by Ravi Sekhar,2015,developed a framework for android clients for keeping track through a few applications.This GPS for recognizing the area of the individual in a bad position.

[2] A mobile women's safety application. The client can unquestionably and carefully activate the call capability by shaking his phone or by interacting unmistakably with the application UI by means of a direct PANIC catch button on the screen. A message comprising the client's property region, as well as the contact subtleties of a pre-chosen rundown of crisis contacts, is immediately sent to the police. 
[3] In an article, Saad Ahmed Akash ; Md. Al-Zihad ; TamalAdhikari ; Md. AbdurRazzaque ; ArifaSharmin ;

Hear Me is to blow an uproarious alarm at the beneficiary gadget regardless of whether the portable is in quiet mode, expanding the unwavering quality of getting assistance from the relatives or emergency clinic/police headquarters faculty.

[4] ShivaniAhir ; Smit Kapadia ; Jigar Chauhan ; NidhiSanghavi,The Personal Stun-A Smart Device For Women's Safety.A keen application will be created on the android stage which is associated with the gadget by means of bluetooth interface that demonstrates the detected information of the subject to the ICE contacts. Until the gadget is killed it will send the area on the interim of $5 \mathrm{mins}$ and will continue blaring ceaselessly. A savvy application will be created on the android stage which is associated with the gadget by means of bluetooth interface that demonstrates the detected information of the subject to the ICE contacts. Until the gadget is killed it will send the area on the interim of 5 mins and will continue signaling consistently[7],[9],[11].

[5] B.GowriPredeba, N.Shyamala, E.Tamilselvi, S. Ramalakshmi, C.Selsiaulvina. WomenSecurity System GSM and GPS. The GPS and GSM modules are used to send a prepared signal to parents at the police station.

[6] In an article, KalpanaViswanath, Ashish Basu. SafetiPin, a portable application, is one device that has been created to gather information on wellbeing in urban communities. Building on the worldwide procedure of wellbeing reviews, SafetiPin has changed it into a versatile application that publicly supports information and data on instability in urban areas

[7] NodeMCU is a LUA-based open source firmware generated for the ESP8266 wifi chip. By investigating the usefulness of the ESP8266 chip, the NodeMCU firmware accompanies the ESP8266 Development Board / Unit, such as the NodeMCU Development Board.

[9] SanjidaSharmin; Md. Khaliluzzaman; Sayeda Fauzia Khatun ; ShajedaKhanam. ladies just to squeeze catch from that security gadget and a programmed message of the injured individual's area data will be sent to chosen numbers through the application. A computerized message will likewise be sent to the closest police headquarters. Also a voice call will be sent to the main number of contact listctronic framework for ladies.

\section{EXISTING SYSTEM}

Node MCU is a LUA-based open source firmware generated for the ESP8266 wifi chip. By investigating the usefulness of the ESP8266 chip, the NodeMCU firmware accompanies the ESP8266 Development Board / Unit, such as the Node MCU Development Board.These applications need a solitary snap to do this assignment. In any case, when a young lady is in a bad position, there can be times that the young lady isn't fit for taking the telephone and squeezing catch.

The parents may be far away to reach in time to safe their child. So we are proposing a new solution to this harassments Principle drawback: No instant help.

\section{PROPOSED SYSTEM}

1.The proposed idea manages the wellbeing and security of ladies defended by neighborhood.

2. The entire wellbeing switch is converged in a smart band 3. The smart band goes about as a flag transmitter.

4. Router is introduced at certain zone which gives a wide bandwith organize.

5.Alarm fixed at the encompassing houses alerts that specific occupants.

6.The designed device acts as a panic button when a girl gets distressed with harassment situation.

7. It acts like a signal transmitter.

8. A router which is arranged in streets process by demultiplexing .This intermediates the receiver and transmitter.

9. The bells which are arranged at surrounding houses automatically rings when a girl pushes panic button encapsulated in safety device.

10. Thingspeak is used as server which runs on wifi router SSID and Password for storing and retrieving data from the smart band and bells of residential houses.

11. Ubidots application is used for sending the gps location and alert message and email help to predefined contacts and emails.

12. In the mean time, the ring alerts the pre assigned contacts and nearby police station.

In simple procedure, every girl is provided with this smart band and smart bells are inserted to every home in streets. All these bells gets connected to a wifi router which is arranged in every street. When a girl gets distressed,she presses the panic button in smart band then automatically the residential bells gets ringed. Intant help was given to the person who gets distressed by residential people[8],[10],[12].

\section{BLOCK DIAGRAM}

\section{SMART DEVICE:}

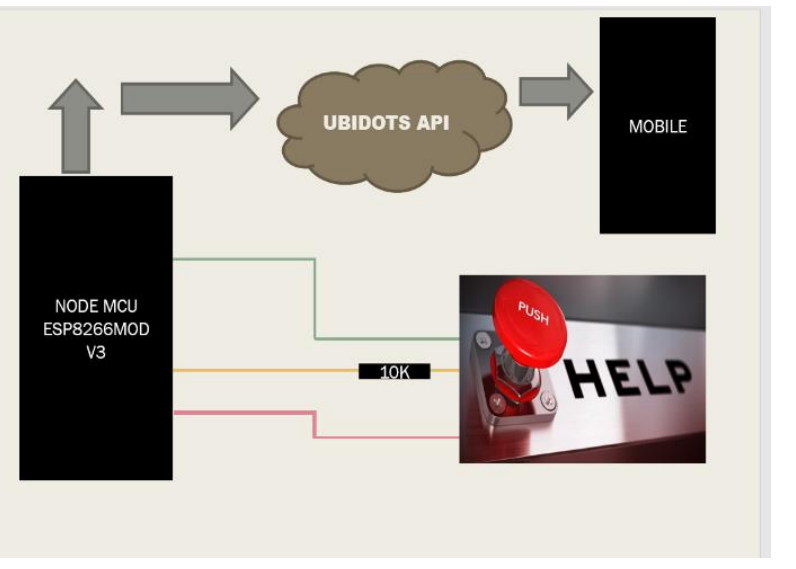




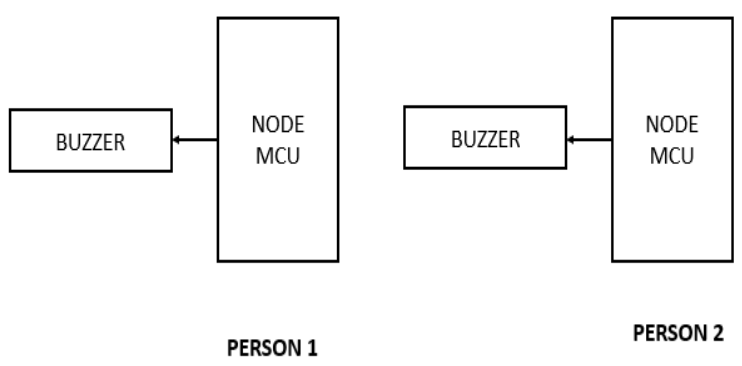

\section{SCHEMATIC DIAGRAM}

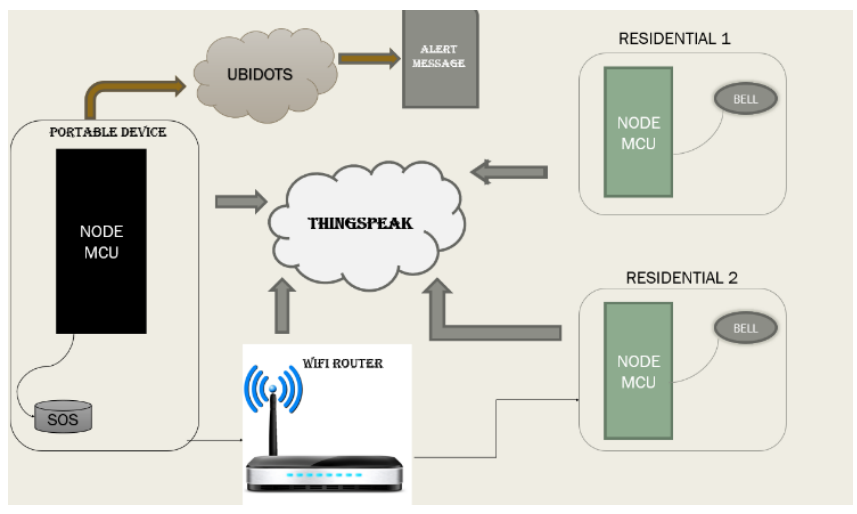

\section{HARDWARE USED}

\section{NODEMCU \\ 2. BELLS \\ 3. PUSH BUTTON \\ 4. WIFI ROUTER}

\section{A. NODEMCU}

NodeMCU is a LUA-based open source firmware generated for the ESP8266 wifi chip. By investigating the usefulness of the ESP8266 chip, the NodeMCU firmware accompanies the ESP8266 Development Board / Unit, such as the NodeMCU Development Board.ESP8266[13],[15],[17]:

The variety of ESP8266 breakout sheets has started to be accessible. The most well-known ones were the ESP-NN system, which often places the $\mathrm{SoC}$ alongside the Flash RAM, the crystal and even the antenna on board. The most notable qualification between the different ESP-NN models is the pins that have been cut out of the ESP8266. Since the ESP8266 was created as a Serial to Wi-Fi connector, the firmware of the ESP8266 updated the AT direction intertrepeter. The original use of the IC was therefore restricted to the use of either a USB to Serial connector or a separate microcontroller (e.g. ATmega328) to perform AT orders over the ESP8266 Serial UART interface. As a consequence, the ESP-01 board rapidly became prominent among the ESP8266 people group due to its $2 \times 4$, 0.1in-pitch connector, which can be effectively attached to a USB serial connector. The connector given access to the pins used for sequential correspondence, to be specific to RX and TX, as

well as 4 control pins, GPIO0, GPIO2, $\mathrm{CH}$ PD and RST (reset), VCC and RST. (reset) next to VCC and GND. However, other ESP-NN sheets provide access to a wider spectrum of pins, despite the fact that their bundling is made of a custom Surface-Mount Device, with castellated sticks as found on the previous related documentation page. We started to explore separate opportunities for the ESP-12E from the distinctive ESP-NNboards[19],[20]. The primary reason is that this module was selected by Node MCU developers for their DevKit 1.0 hardware. Since the ESP8266 offers a intelligent reaction to the quickly increasing business sector of associated web tasks and gadgets (i.e. the so-called Internet Of Things), it has demonstrated to be one of the most well-known advancement stages of the last 18 months. As a consequence, the committed network aligned with the stage that concentrated on improving its usefulness. First of all, distinctive firmware decisions have been produced to maintain the ESP8266 running, making it feasible from a straightforward Serial to Wi-Fi connector to a fully utilitarian microcontroller with access to its GPIO and equipment-based capacities such as PWM, I2C, 1-Wire correspondence, and ADC; this, of course, notwithstanding the fact that it is still available.

\section{B. WIFI ROUTER}

Wi-Fi is an innovation in radio distant gadget neighbourhoods that are subject to IEEE 802.11 norms. Wi-Fi is a trademark of the Wi-Fi Alliance, which limits the use of the term Wi-Fi Certified to items that perform total interoperability affirmation tests effectively.

\section{SOFTWARE USED}

\section{ARDUINO C \\ 2. ARDUINO IDE \\ 3. UBIDOTS \\ 4. THINGSPEAK}

\section{A. THINGSPEAK}

ThingSpeak is a free IOT app,which is utilized to peruse and compose information that investigated from the things utilizing web. ThingSpeak engages the generation of sensor logging applications, territory following applications, and a casual network of things with announcements".

ThingSpeak was at first moved by ioBridge in 2010 as an organization in help of IoT applications.

ThingSpeak has joined assistance from the numerical figuring programming MATLAB from MathWorks,permittingThingSpeak customers to examine and picture exchanged data using Matlab.

ThingSpeak has a comfortable relationship with Mathworks, Inc. To be sure, most of the ThingSpeak documentation is joined into the Mathworks' Matlab documentation site page and despite engaging enlisted Mathworks customer accounts as real login capabilities on the ThingSpeak site. 
The terms of administration and insurance strategy of ThingSpeak.com are between the agreeing customer and Mathworks, Inc.

It has been the subject of articles specifically "Designer" locales like Instructables, Codeproject, and Channel 9.

\section{B. UBIDOTS}

Ubidots offers a stage for designers that empowers them to effortlessly catch sensor information and transform it into valuable data. Utilize the Ubidots stage to send information to the cloud from any Internet-empowered gadget. You would then be able to Configure activities and alarms dependent on your constant information and open the estimation of your information through visual instruments. Ubidots offers a REST API that enables you to peruse and compose information to the assets accessible: information sources, factors, qualities, occasions and bits of knowledge. The API bolsters both HTTP and HTTPS and an API Key is required[14],[16],[18].

\section{USER DATA SOURCE}
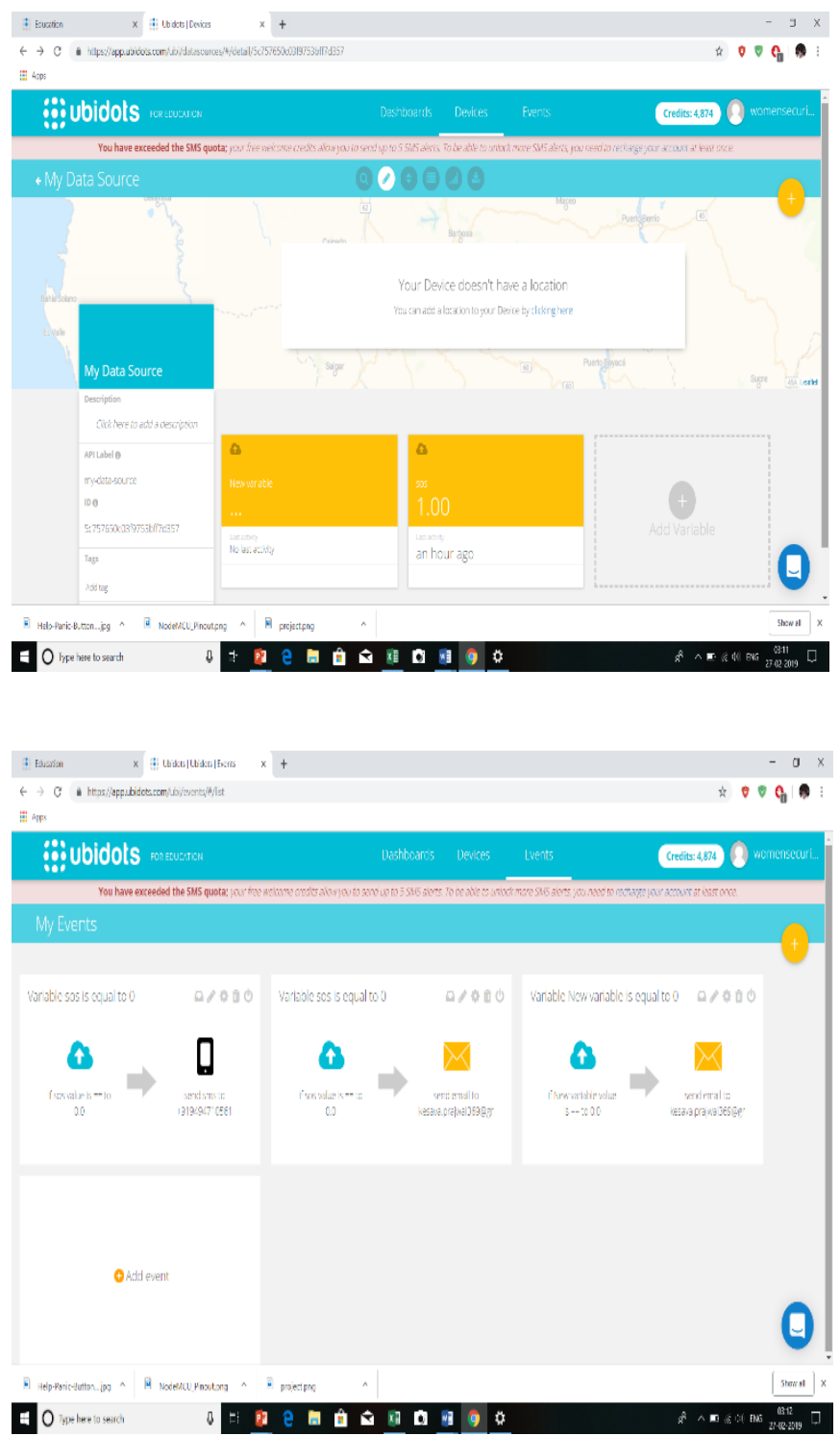

\section{OUTPUT}

\section{OUTPUT}

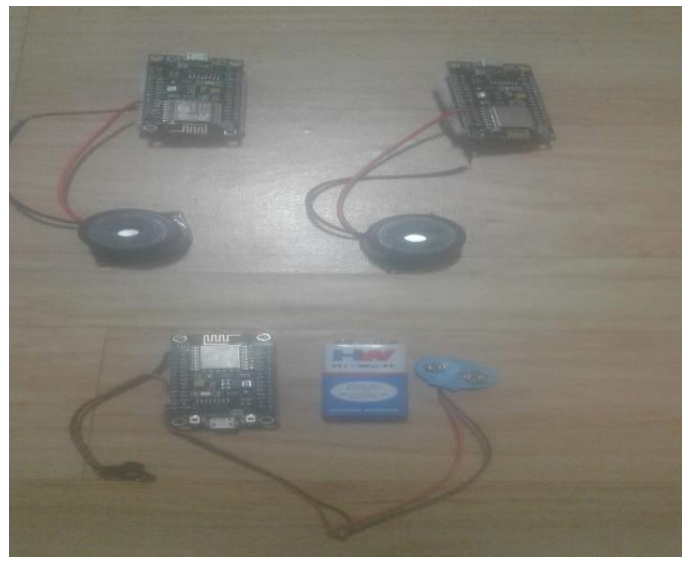

\section{GPS LOCATION}

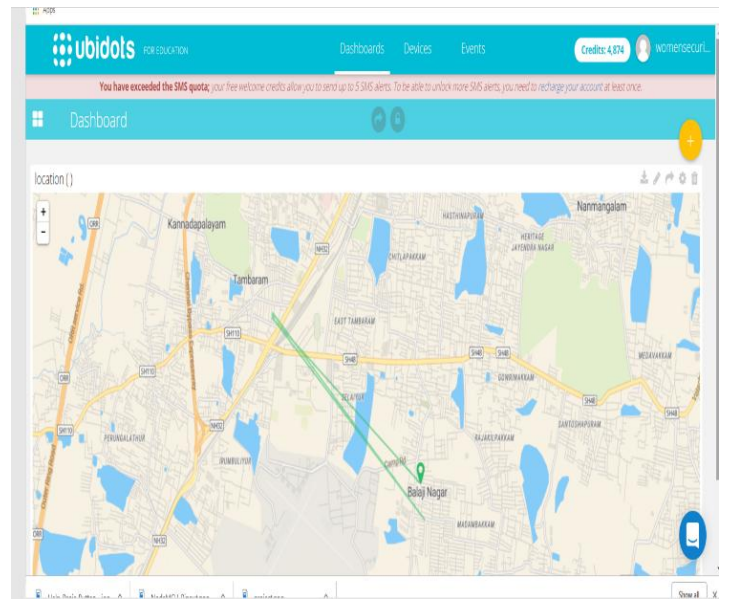

\section{ADVANTAGES}

- Instant response

- User friendly

- Highly secured

- Strictly prank prohibited

- Less power consumption

- Scalable

- Portable

\section{CONCLUSION}

As a consequence, the committed network aligned with the stage that concentrated on improving its usefulness. First of all, distinctive firmware decisions have been produced to maintain the ESP8266 running, making it feasible from a straightforward Serial to Wi-Fi connector to a fully utilitarian microcontroller with access to its GPIO and equipment-based capacities such as PWM, I2C, 1-Wire correspondence, and ADC; this, of course, notwithstanding the fact that it is still available. 


\section{REFERENCES}

1. G Kongkham, D. \& Sundararajan, M. 2019, "Distributed wideband sensing method for faded dynamic spectrum access", International Journal of Innovative Technology and Exploring Engineering, vol. 8, no. 10, pp. 4309-4312.

2. Balaji, S., John Paul Praveen, A. \& Mohanraj, R. 2019, "Recognizable proof and analysis of palm print in biometric authentication system using bayes techniques", International Journal of Innovative Technology and Exploring Engineering, vol. 8, no. 9 Special Issue 3, pp. 1126-1129.

3. Kavitha, G., Priya, N., Velvizhi, R. \& Allin Geo, A.V. 2019, "Parallel computation in correspondence and signal processing", International Journal of Innovative Technology and Exploring Engineering, vol. 8, no. 9 Special Issue 3, pp. 1136-1139.

4. Hema, R., Sundararajan, M. \& Balaji, S. 2019, "Smartphone control robot with automatic firing gun", International Journal of Innovative Technology and Exploring Engineering, vol. 8, no. 9 Special Issue 3, pp. 625-627.

5. Kaliyamurthie, K.P., Sundar Raj, B., Velvizhi, R. \& Shanmugapriya, K. 2019, "Dual band paper substrate CPW antenna for wireless applications", International Journal of Innovative Technology and Exploring Engineering, vol. 8, no. 9 Special Issue 3, pp. 605-608.

6. Geo, A.V.A., Arunachalam, A.R., Michael, G. \& Elankavi, R. 2019, "Evaluating architecture using compact modalities", International Journal of Innovative Technology and Exploring Engineering, vol. 8, no. 9 Special Issue 3, pp. 836-838.

7. Theivasigamani, S., Jeyapriya, D. \& Anita Davamani, K. 2019, "Anamoly analyzing and exploring for wireless sensor networks", International Journal of Innovative Technology and Exploring Engineering, vol. 8, no. 9 Special Issue 3, pp. 1116-1118.

8. Jeyapriya, D., Theivasigamani, S., Velvizhi, R. \& Nandhini, P. 2019, "Program detection in wireless feeler networks", International Journal of Innovative Technology and Exploring Engineering, vol. 8, no. 9 Special Issue 3, pp. 1194-1195.

9. Gowri Sankaran, B., Karthik, B. \& Vijayaragavan, S.P. 2019, "Image compression utilizing wavelet transform", International Journal of Innovative Technology and Exploring Engineering, vol. 8, no. 10, pp. 4305-4308.

10. Gowri Sankaran, B., Karthik, B. \& Vijayaragavan, S.P. 2019, "Weight ward change region plummeting change for square based image huffman coding", International Journal of Innovative Technology and Exploring Engineering, vol. 8, no. 10, pp. 4313-4316.

11. Hema, R., Sundararajan, M. \& Balaji, S. 2019, "Smartphone control robot with automatic firing gun", International Journal of Innovative Technology and Exploring Engineering, vol. 8, no. 9 Special Issue 3, pp. 625-627.

12. Rangaswamy, K. \& Rajabhushanam, C. 2019, "Congestion control in wireless network using TCP friendly rate control (TFRC)", International Journal of Recent Technology and Engineering, vol. 8, no. 2 Special issue 3, pp. 1598-1602.

13. Tamil Selvan, S. \& Sundararajan, M. 2019, "Performance Parameters of 3 Value 8t Cntfet Based Sram Cell Design Using H-Spice", International Journal of Recent Technology and Engineering, vol. 8, no. 2 Special issue 5, pp. 22-27.

14. Vinoth, V.V. \& Kanniga, E. 2019, "Steganographical techniques in hiding text images - system", International Journal of Recent Technology and Engineering, vol. 8, no. 2, pp. 6535-6537.

15. Saravana, S., Balaji, S., Arulselvi, S. \& John Paul Praveen, A. 2019 "Reliable power quality monitoring and protection system", International Journal of Innovative Technology and Exploring Engineering, vol. 8, no. 9 Special Issue 3, pp. 644-645.

16. Sundaramoorthy, A. \& John Wiselin, M.C. 2019, "Single patch antenna with multiple feed", International Journal of Innovative Technology and Exploring Engineering, vol. 8, no. 9, pp. 1743-1747.

17. Velavan, R., Bharanidharan, S. \& Sheeba, B. 2019, "EMF pollution Causes, effects and protection", International Journal of Innovative Technology and Exploring Engineering, vol. 8, no. 9 Special Issue 3, pp. 1166-1168.

18. Veer, R.A., Arulselvi, S. \& Karthik, B. 2019, "Construction of ensemble square classification approaches in MIMO OFDM", International Journal of Engineering and Advanced Technology, vol. 8, no. 5, pp. 2039-2041.

19. Agitha, W. \& Kaliyamurthie, K.P. 2019, "Improved energy efficient in WBAN using MAC with cloud computing", International Journal of Innovative Technology and Exploring Engineering, vol. 8, no. 8, pp. 2405-2408.

20. Kastro, G.G. \& Wiselin, M.C.J. 2019, "Design and analysis of stub loaded resonator", International Journal of Recent Technology and Engineering, vol. 8, no. 1 Special Issue4, pp. 272-283.

\section{AUTHORS PROFILE}

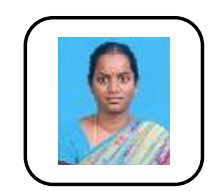

S.Philomina, Assistant Professor, Department of Electronics and Communication Engineering, Bharath Institute of Higher Education and Research, Chennai, India.

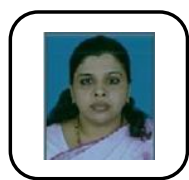

M. Jasmine, Assistant Professor, Department of Electronics and Communication Engineering, Bharath Institute of Higher Education and Research, Chennai, India.

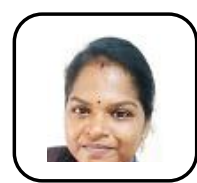

K. Subbulakshmi, Assistant Professor, Department of Electronics and Communication Engineering, Bharath Institute of Higher Education and Research, Chennai, India. 